\title{
An Approach for Magnetic Halloysite Nanocomposite with Selective Loading of Superparamagnetic Magnetite Nanoparticles in the Lumen
}

Hady Hamza, ${ }^{a}$ Anna Maria Ferretti, ${ }^{b}$ Claudia Innocenti, ${ }^{c, d, e}$ Katarzyna Fidecka, ${ }^{a}$ Emanuela Licandro, ${ }^{a}$ Claudio Sangregorio, ${ }^{\mathrm{c}, \mathrm{d}, \mathrm{e}, *}$ Daniela Maggioni ${ }^{\mathrm{a}, \mathrm{d}, *}$

${ }^{a}$ Dipartimento di Chimica, Università degli Studi di Milano, Via Golgi 19, 20133 Milano, Italy

${ }^{b}$ SCITEC-CNR, Sede Secondaria via G. Fantoli 16/15, 20138 Milano, Italy

' ICCOM-CNR, via Madonna del Piano 10, 50019 Sesto Fiorentino, Italy

${ }^{d}$ Consorzio INSTM, Via G. Giusti, 9, 50121, Firenze, Italy

e Dipartimento di Chimica, Università degli Studi di Firenze, via della Lastruccia 3, 50019 Sesto Fiorentino, Italy

*Corresponding author: daniela.magaioni@unimi.it 
Syntheses of SPION@OA, ligand exchange processes, attempts for the loading of negative charged SPION in the lumen of HNT and one-pot loading attempt are described here following.

1 Synthesis of SPION1@OA by a coprecipitation method in a biphasic system with $\mathrm{NaOH}$. The synthesis was carried out by following a slightly modified literature procedure. ${ }^{1}$ Briefly, in a two-neck round-bottom flask, sodium oleate $(4 \mathrm{mmol}, 1.218 \mathrm{~g})$, anhydrous $\mathrm{FeCl}_{3}(1 \mathrm{mmol}, 0.162 \mathrm{~g}), \mathrm{FeCl}_{2} \cdot 4 \mathrm{H}_{2} \mathrm{O}$ $(0.5 \mathrm{mmol}, 0.099 \mathrm{~g})$ and $\mathrm{NaOH}(3 \mathrm{mmol}, 0.122 \mathrm{~g})$ were dissolved in a mixture of deoxygenated water (by bubbling $\mathrm{N}_{2}$ gas for $30 \mathrm{~min}, 3.0 \mathrm{~mL}$ ), ethanol $(3 \mathrm{~mL}$ ) and toluene $(5.25 \mathrm{~mL}$ ) under nitrogen. The mixture was refluxed at $74{ }^{\circ} \mathrm{C}$ for $4 \mathrm{~h}$. Then the final black mixture was left to return to room temperature by removing the heat source. The suspension was precipitated with ethanol and the sediment was isolated by magnetic decantation. The precipitate was dispersed in toluene and centrifuged for $10 \mathrm{~min}$ at $7142 \mathrm{rcf}$ to remove all the undispersed residues. The black toluene dispersion was precipitated with ethanol again and the solvent was removed through magnetic separation. Finally, SPIONs were redisposed in $40 \mathrm{~mL}$ toluene to form stable colloids and stored under nitrogen at $-23^{\circ} \mathrm{C}$ for further uses. Fe content by UV-vis spectroscopy was $3.3 \mathrm{mg} / \mathrm{mL}$.

2 Synthesis of SPION2@OA by a coprecipitation method in a biphasic system without $\mathrm{NaOH}$. The synthesis was carried out by following the same procedure already reported previously, but in the absence of $\mathrm{NaOH}^{1}{ }^{1}$ Briefly, in a two-neck round-bottom flask, sodium oleate $(8 \mathrm{mmol}, 2.44 \mathrm{~g})$, anhydrous $\mathrm{FeCl}_{3}(1 \mathrm{mmol}, 0.162 \mathrm{~g})$, and $\mathrm{FeCl}_{2} \cdot 4 \mathrm{H}_{2} \mathrm{O}(0.5 \mathrm{mmol}, 0.099 \mathrm{~g})$ were dissolved in a mixture of deoxygenated water (by bubbling $\mathrm{N}_{2}$ gas for $30 \mathrm{~min}, 2.25 \mathrm{~mL}$ ), ethanol $(3 \mathrm{~mL})$ and toluene $(5.25 \mathrm{~mL})$ under nitrogen atmosphere. The mixture was refluxed at $74^{\circ} \mathrm{C}$ for $4 \mathrm{~h}$. Then, the work-up, the recovery and the final storage of the NPs was as for the NPs obtained for coprecipitation in a biphasic system in the presence of $\mathrm{NaOH}$. Fe content by UV-vis spectroscopy was $4 \mathrm{mg} / \mathrm{mL}$.

3 Synthesis of SPION3@OA by a thermal decomposition method. The synthesis was carried out by following a slightly modified literature procedure. ${ }^{2}$ Birefly, in a two-neck round-bottom flask, Fe(acac) 3 (0.353 g, $1 \mathrm{mmol}$ ), 1,2-hexadecanediol (1.435 g, $5 \mathrm{mmol}$ ), oleic acid (0.952 mL, $3 \mathrm{mmol}$ ), and $0.987 \mathrm{~mL}$ of oleylamine ( $3 \mathrm{mmol}$ ) were dissolved in $10 \mathrm{~mL}$ phenyl ether by magnetic stirring for 10 min under a nitrogen atmosphere. After having removed the magnetic stirrer, the mixture was heated at $15^{\circ} \mathrm{C} / \mathrm{s}$ from room temperature to $200^{\circ} \mathrm{C}$ and left at this final temperature for $35 \mathrm{~min}$. Then, under a blanket of nitrogen, the mixture was further heated up to $265^{\circ} \mathrm{C}$ at $15^{\circ} \mathrm{C} / \mathrm{s}$ and left at this temperature for 35 min. Finally, the black-brown mixture was naturally cooled by removing the heat source to room temperature. The so-obtained suspension was precipitated with ethanol $(20 \mathrm{~mL})$, then the black precipitate was separated via centrifugation (10 min at $4226 \mathrm{rcf}$ ), then it was dissolved in $20 \mathrm{~mL} \mathrm{n}$ hexane in the presence of oleic acid $(0.05 \mathrm{~mL})$ and oleylamine $(0.05 \mathrm{~mL})$. Centrifugation $(10 \mathrm{~min}$ at 
4226 rcf) was applied to remove any undispersed residue. The SPION@OA were then re-precipitated with $40 \mathrm{~mL}$ ethanol, centrifuged (10 $\mathrm{min}$ at $4226 \mathrm{rcf}$ ) to remove the solvent, then re-dispersed in 15 $\mathrm{mL} \mathrm{n}$-hexane and stored under nitrogen at $-23^{\circ} \mathrm{C}$ for further uses. Fe content by AAS was $2.2 \mathrm{mg} / \mathrm{mL}$.

4 Synthesis of SPION4@OA by a thermal decomposition method. The synthesis was carried out by following a slightly modified literature procedure. ${ }^{3}$ Briefly, in a two-neck round-bottom flask, ironoleate (1.37 g, $1.53 \mathrm{mmol})$, 1,2-hexadecanediol (1.185 g, $4.596 \mathrm{mmol})$ and oleic acid $(0.448 \mathrm{~mL}, 1.41$ mmol) were dissolved in $7.14 \mathrm{~mL}$ diphenyl ether by magnetically stirring for 10 min under a nitrogen atmosphere. The mixture was degassed at $90^{\circ} \mathrm{C}$ under vacuum and stirring for $2 \mathrm{~h}$. The mixture was then heated at $10{ }^{\circ} \mathrm{C} / \mathrm{min}$ from 90 to $260^{\circ} \mathrm{C}$, and left at this final temperature for $30 \mathrm{~min}$ under nitrogen. Finally, the black-brown mixture was rapidly cooled by removing the heat source, and water bath till reach to room temperature. The so-obtained suspension was precipitated with acetone (50 $\mathrm{mL}$ ), and the black precipitate was separated via centrifugation (10 min at $4226 \mathrm{rcf}$ ). After that, it was dissolved in $10 \mathrm{~mL} \mathrm{n}$-hexane, re-precipitated with $50 \mathrm{~mL}$ ethanol, centrifuged (10 min at $4226 \mathrm{rcf}$ ), redispersed in $35 \mathrm{~mL} n$-hexane, and finally stored under nitrogen at $-23^{\circ} \mathrm{C}$ for further uses. Fe content by UV-vis spectroscopy $=1.9 \mathrm{mg} / \mathrm{mL}$.

5 Attempts to fill HNT with negatively charged SPION. We started preparing SPION1@OA ${ }^{1}$ where OA stands for oleic acid, with a hydrodynamic diameter of $13.5 \pm 4 \mathrm{~nm}$ (see DLS measurement reported in Figure S1), which was slightly smaller than the average inner HNT diameter.
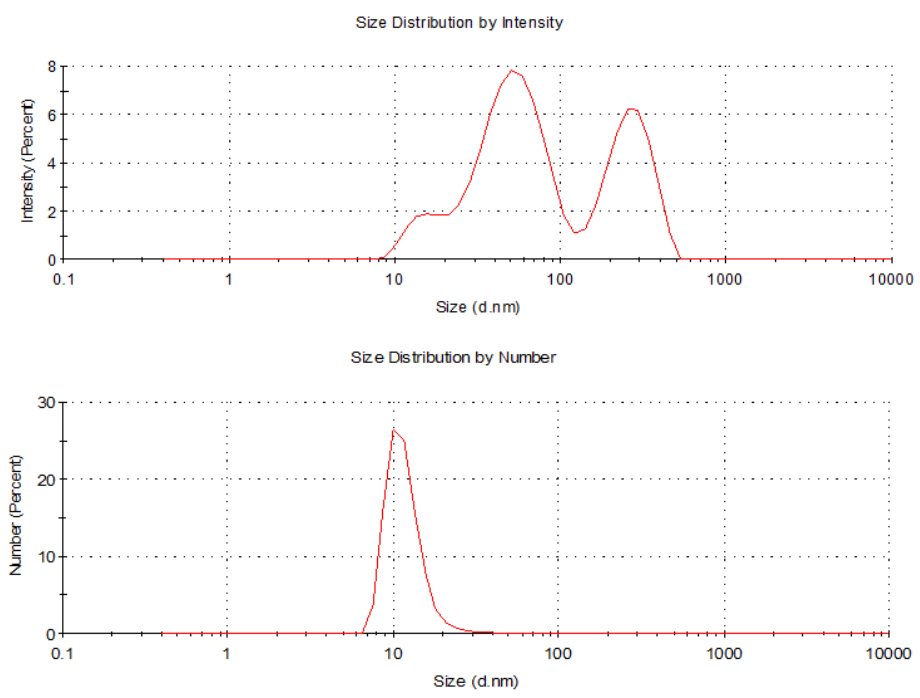

Figure S1. DLS of SPION1@OA suspended in n-hexane, synthesised by a coprecipitation method in a biphasic system and in the presence of $\mathrm{NaOH}$. Top: Intensity-weighted diameter distribution, showing the presence of three distinct populations centred at $13.5 \mathrm{~nm}, 50 \mathrm{~nm}$ and $270 \mathrm{~nm}$. Bottom: Number-weighted diameter distribution, showing that the large majority of the NPs belong to the smaller population, being the other two ascribable to sporadic aggregates. 
In order to prepare negatively charged NPs, the oleate molecular layer was removed and substituted with a proper negatively charged stabilizing molecule. Hence, a first ligand exchange process was carried out with the bi-functional molecule dimercaptosuccinic acid (DMSA), ${ }^{4}$ which is able on one side to bind to the surface and on the other side to self-deprotonate, giving rise to negatively charged as well as water-compatible SPION. The ligand exchange possibly needs to occur without NP aggregation, hence maintaining the hydrodynamic size observed on the starting SPION stabilized by OA. After the ligand exchange step, the SPION1@DMSA showed a hydrodynamic diameter suitable for the HNT loading (see Figure S2a).
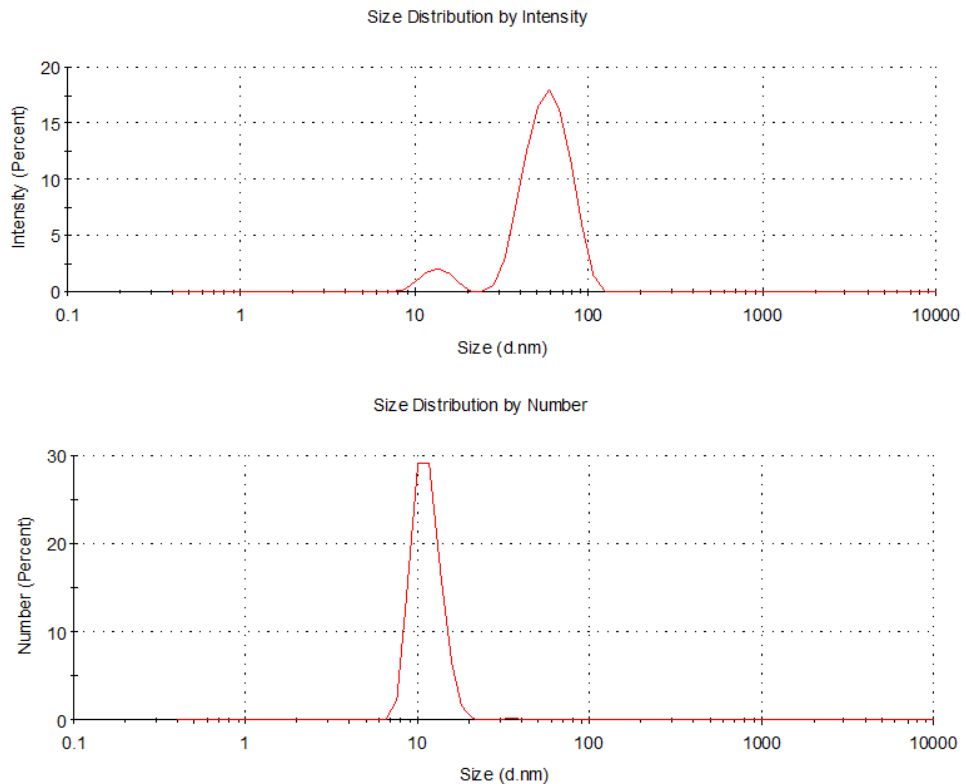

Figure S2a. DLS of SPION1@DMSA suspended in milliQ water after ligand exchange from SPION1@OA. Top: Intensity-weighted diameter distribution, showing the presence of two distinct populations centred at $13.5 \mathrm{~nm}$ and $60 \mathrm{~nm}$. Bottom: Number-weighted diameter distribution, showing that the large majority of the NPs belong to the smaller population, being the other ascribable to sporadic aggregates of the main single NPs.

The loading tests were then carried out bringing the starting pristine-halloysite suspension to acidic $\mathrm{pH}(\sim 3-4)$ in order to maximize the charge difference between the inner part of HNT (still enough positive at this $\mathrm{pH}$ ) and the magnetic nanoparticle (still largely negative). However, both sonication and/or applied vacuum/ $\mathrm{N}_{2}$ cycles - to induce the air bubbles naturally present in the halloysites to come out, as well as the NPs of opposite charge to enter in the lumen - were not effective, and SPION were not found in the HNT inner part by TEM investigation. On the contrary, they always formed aggregates accumulating outside the nanoclay, and in some cases interacting with the HNT edges only (Figure S2b). 


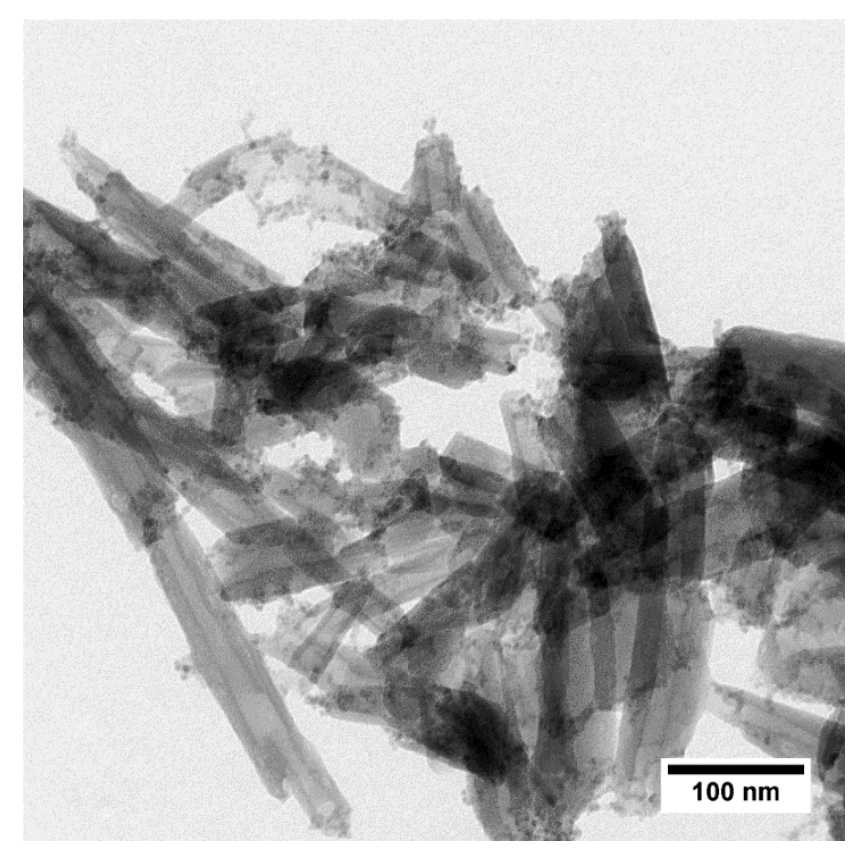

Figure S2b. TEM micrograph of pristine HNT treated with SPION1@DMSA in water suspension by vacuum/nitrogen cycles and sonication.

We then considered decreasing the size of the SPION by adopting different synthetic approaches for SPION2@OA (with a hydrodynamic diameter of $10.6 \pm 4 \mathrm{~nm},{ }^{1}$ see DLS size distribution in Figure S3) and SPION3@OA (with a hydrodynamic diameter of $8.0 \pm 1.9$ nm, see DLS size distribution in Figure S4a, and a mean diameter by TEM of $5.1 \pm 1.6 \mathrm{~nm},{ }^{2}$ Figure S4b).
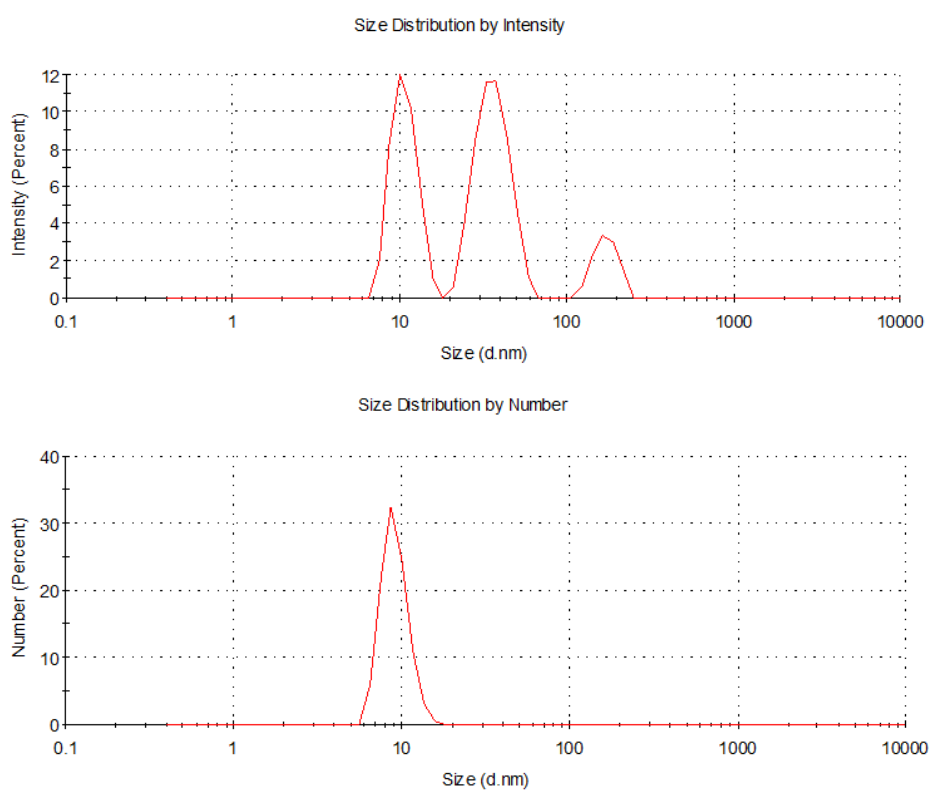

Figure S3. DLS of SPION2@OA suspended in n-hexane, synthesised by a coprecipitation method in a biphasic system without $\mathrm{NaOH}$. Top: Intensity-weighted diameter distribution, showing the presence of three distinct populations centred at $10.6 \mathrm{~nm}, 35 \mathrm{~nm}$ and $150 \mathrm{~nm}$. Bottom: Number-weighted diameter distribution, showing that the large majority of the NPs belong to the smaller population, being the other two due to sporadic aggregates. 

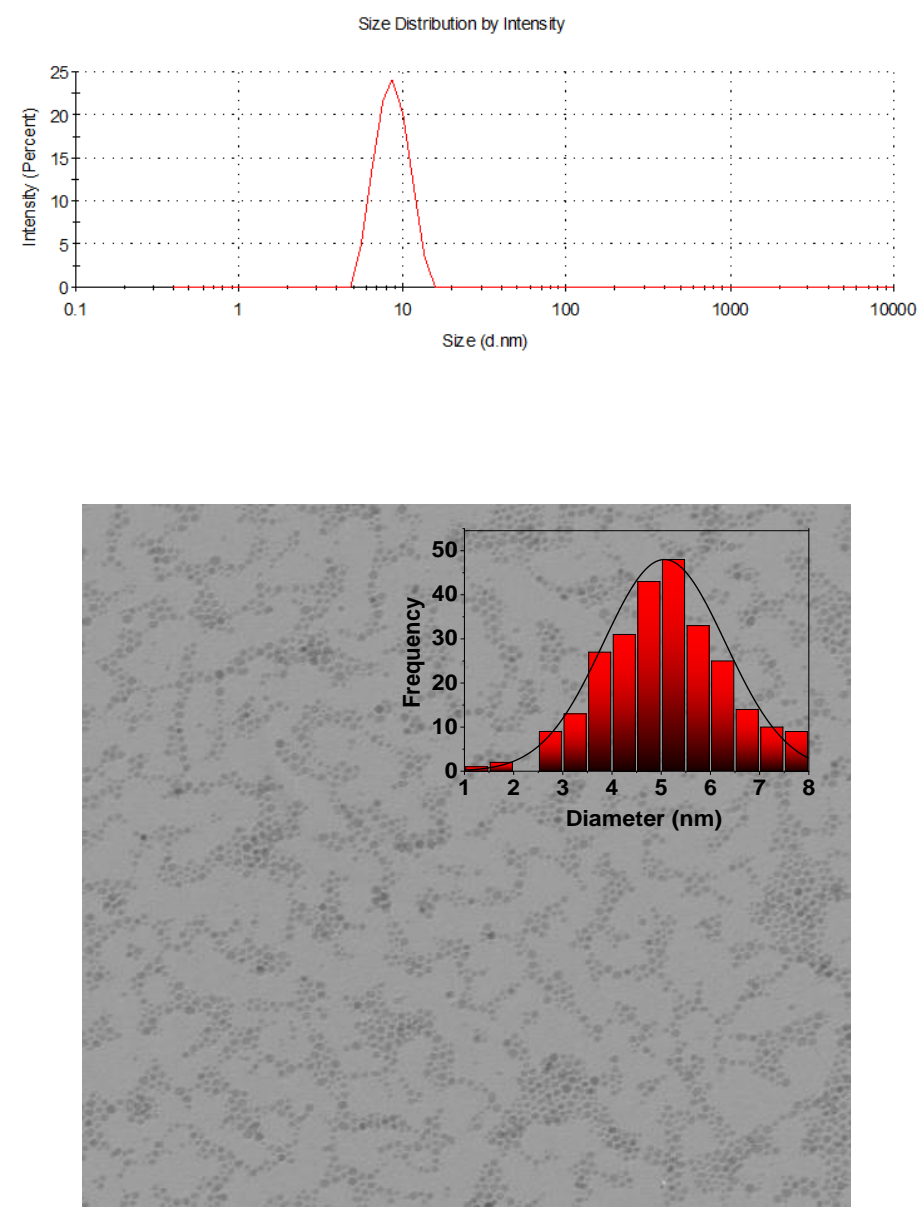

Figure S4. Top: Intensity-weighted diameter distribution by DLS measurements on SPION3@OA suspended in n-hexane, synthesised by a thermal decomposition method. Bottom: TEM micrograph of the same sample. In the inset it is reported the size distribution derived by Image-J software.

In both cases, as already previously done on bigger SPION, the oleate layer onto NPs was exchanged with DMSA. It is noteworthy that many times the ligand exchange OA/DMSA leads to the formation of aggregates, and the $\mathrm{pH}$ of the exchange process played a fundamental role. Indeed, if the ligand exchange is carried out in basic conditions ( $\mathrm{pH} 9-10)$, the final colloidal water dispersions are much more stable, indicating that a more effective exchange is occurring. In any case, even when the hydrodynamic diameter was small enough, the negatively charged NPs were not able to enter into the HNT lumen (Figure S5). 


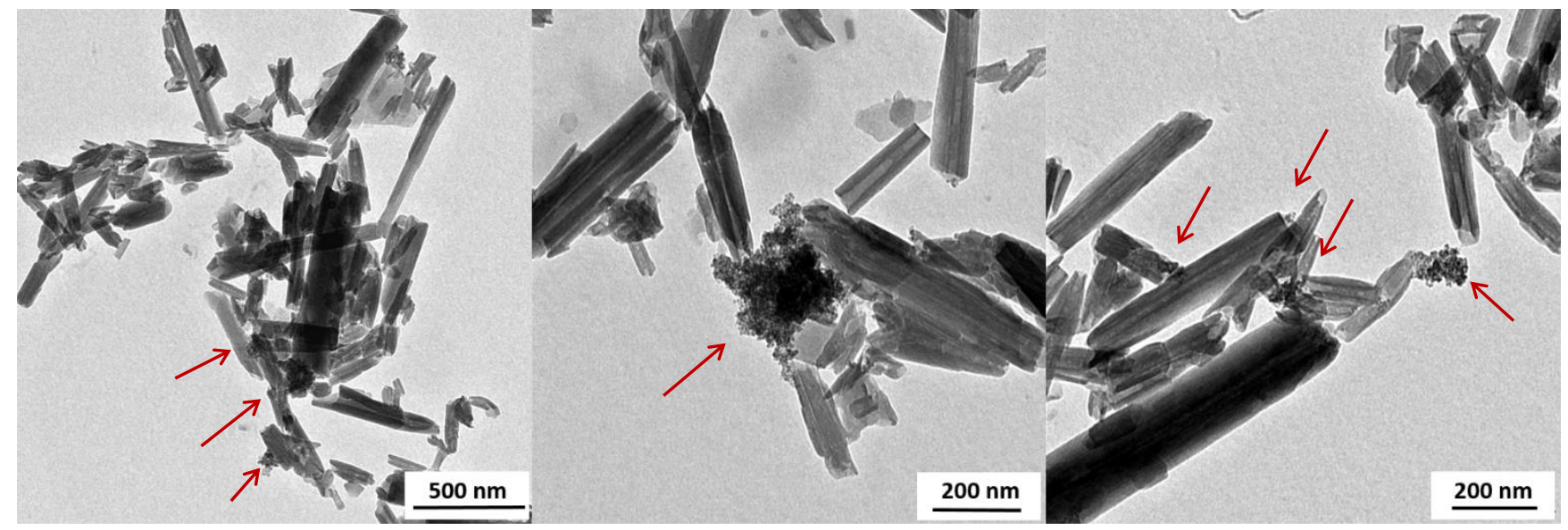

Figure S5. TEM images of pristine HNT treated with SPION3@DMSA in water suspension by vacuum/nitrogen cycles. Red arrows indicate the sites of SPIONs accumulation.

To explain the unsuccessful loading process, the hypothesis is that the DMSA could induce early aggregation of SPION during the reduced pressure/ $\mathrm{N}_{2}$ process, especially at acidic $\mathrm{pH}$ values. DMSA could form S-S bridges or hydrogen bonds between DMSA molecules lying onto different SPION, especially when they are pushed to stay in a small volume. Thus, we changed the type of hydrophilic coating, employing other bi-functional molecules, i.e. gallic acid (GA), ${ }^{5}$ 16-phosphonohexadecanoic acid (PDA) and protocatechuic acid (PA) or the peptizing agent tetramethylammonium hydroxide $(\mathrm{TMAOH})^{6}$ (see Scheme S1). Except of PDA that did not give good suspensions after the ligand exchange, all the other molecules tested (see Scheme 2) effectively displaced the oleate molecules from the NP surface, giving rise to stable water colloids (see Figures S6-S8 for DLS measurements and Figures S5 and S7 for TEM images of SPION4@GA and SPION4@PA, respectively). Nevertheless, in no case we did get the loading in the HNT inner.<smiles>O=C(O)C(S)C(S)C(=O)O</smiles>

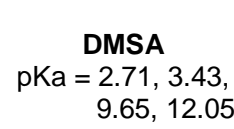

$9.65,12.05$<smiles>C[N+](C)(C)O</smiles><smiles>O=C(O)c1cc(O)c(O)c(O)c1</smiles>

GA $\mathrm{pKa}=4.5,10$<smiles>O=C(O)c1ccc(O)c(O)c1</smiles>

PA

$\mathrm{pKa}=4.45$

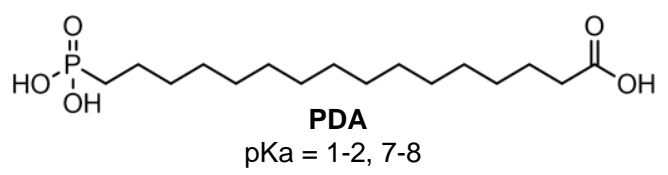

Scheme S1. Scheme of bifunctional ligands used for the OA exchange on SPION with their pKa. 
Size Distribution by Intensity

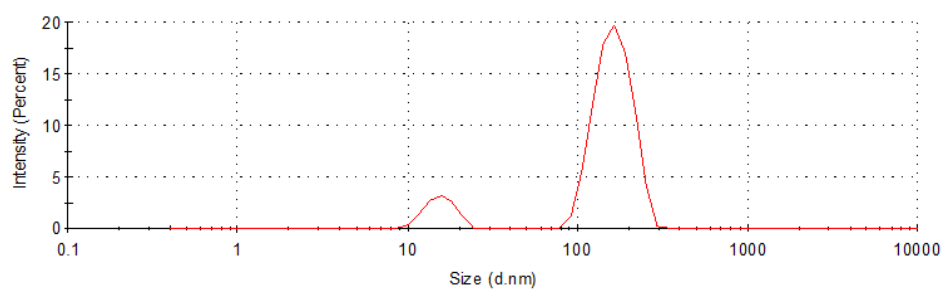

Size Distribution by Number

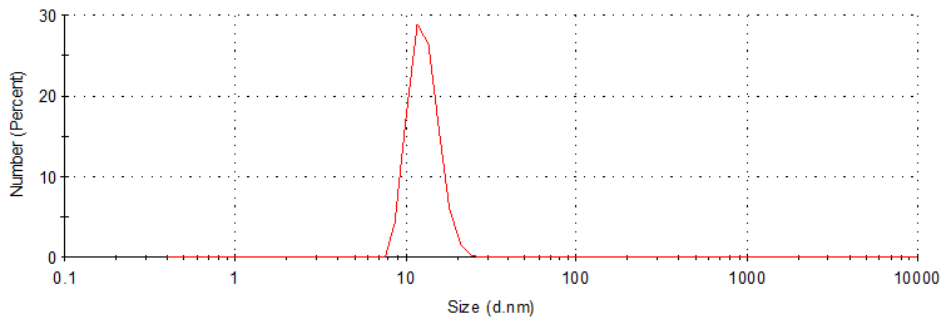

Figure S6a. DLS of SPION4@GA SPIONs suspended in MilliQ water after ligand exchange. Top: Intensity-weighted diameter distribution, showing the presence of two distinct populations centred at $13.0 \mathrm{~nm}$ and $160 \mathrm{~nm}$. Bottom: Number-weighted diameter distribution, showing that the large majority of the NPs belong to the smaller population, being the other ascribable to sporadic aggregates of the main single NPs.

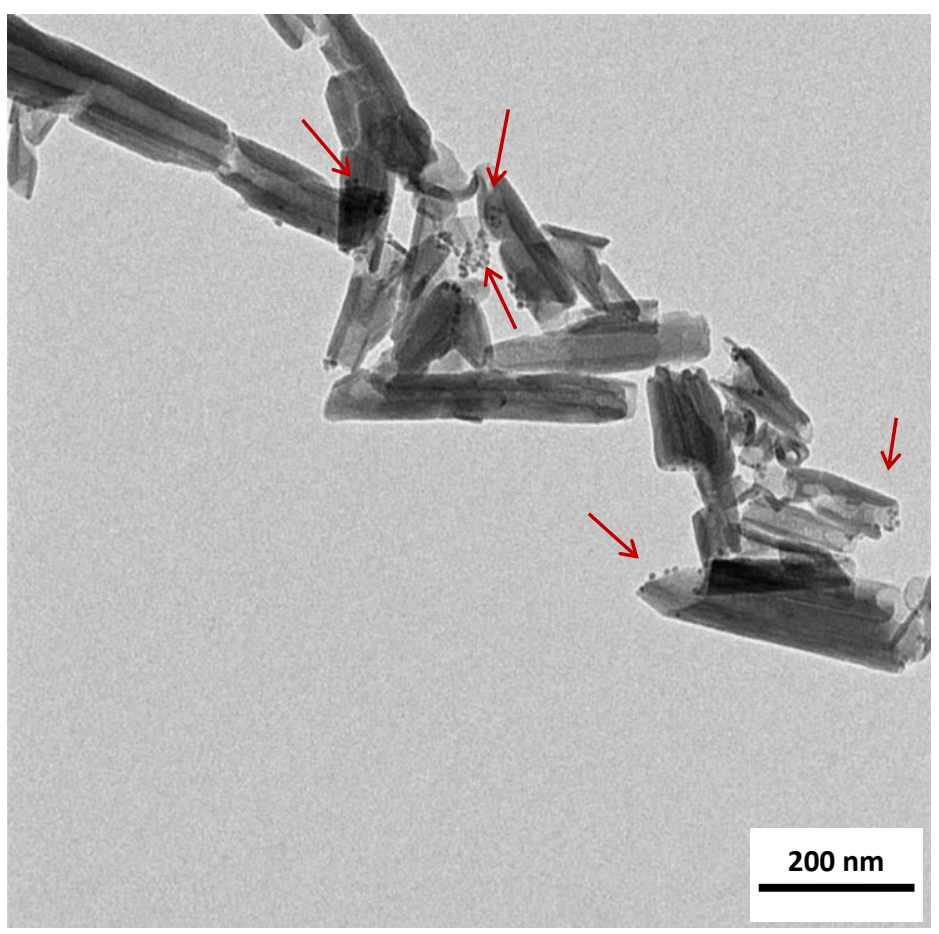

Figure S6b. TEM micrograph of pristine HNT treated with SPION4@GA in water suspension by vacuum/nitrogen cycles. Red arrows indicate the sites of SPIONs accumulation. 
Size Distribution by Intensity

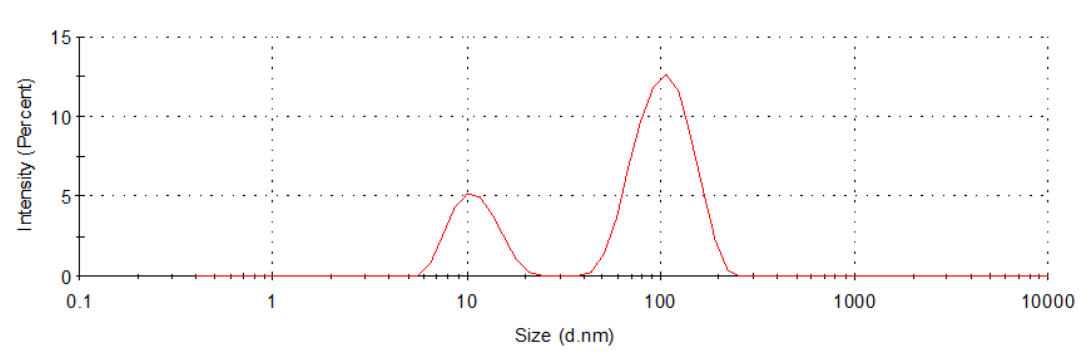

Size Distribution by Number

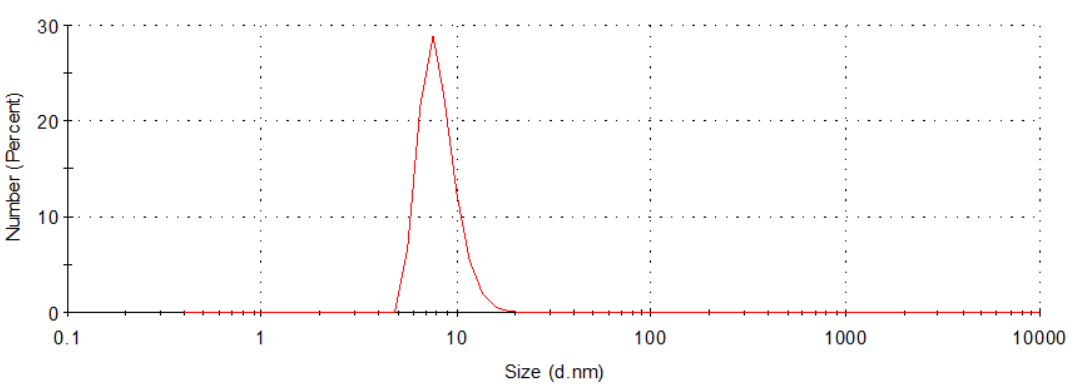

Figure S7. DLS of SPION4@TMAOH suspended in MilliQ water after ligand exchange. Top: Intensity-weighted diameter distribution, showing the presence of two distinct populations centred at $10.0 \mathrm{~nm}$ and $100 \mathrm{~nm}$. Bottom: Number-weighted diameter distribution, showing that the large majority of the NPs belong to the smaller population, being the other ascribable to sporadic aggregates of the main single NPs.

Contrary to what observed for the other samples of SPION covered with DM SA, GA and PA, in the case of SPION4@TMAOH loading test, we did not observe any change in color of the recovered powders as well as any magnetic attraction when an external magnet was applied, and no TEM image was acquired. 

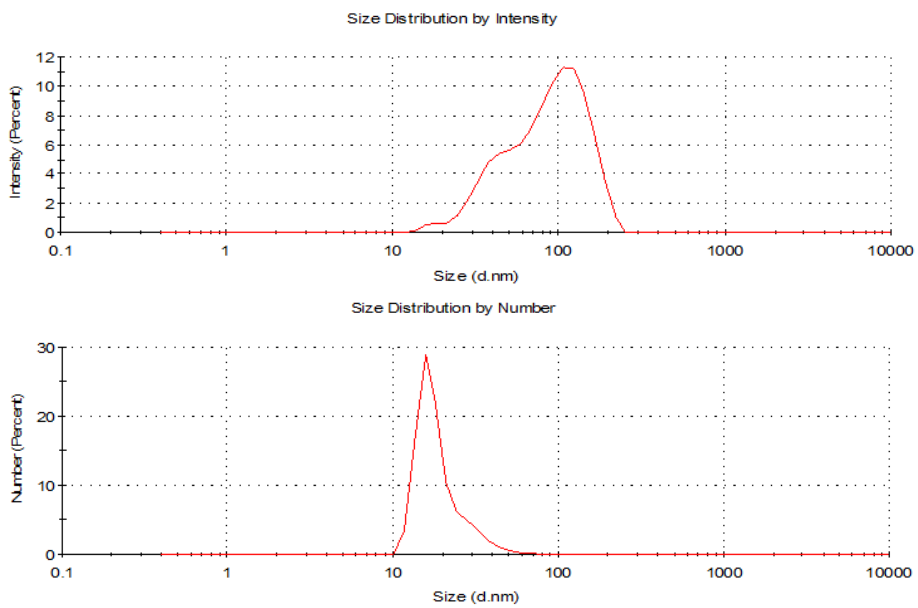

Figure S8a. DLS of SPION4@PA suspended in milliQ water. Top: Intensity-weighted diameter distribution, showing the presence of three distinct populations centred at $13.0 \mathrm{~nm}, 40 \mathrm{~nm}$ and $102 \mathrm{~nm}$. Bottom: Numberweighted diameter distribution, showing that the large majority of the NPs belong to the smaller population, being the other two ascribable to sporadic aggregates.

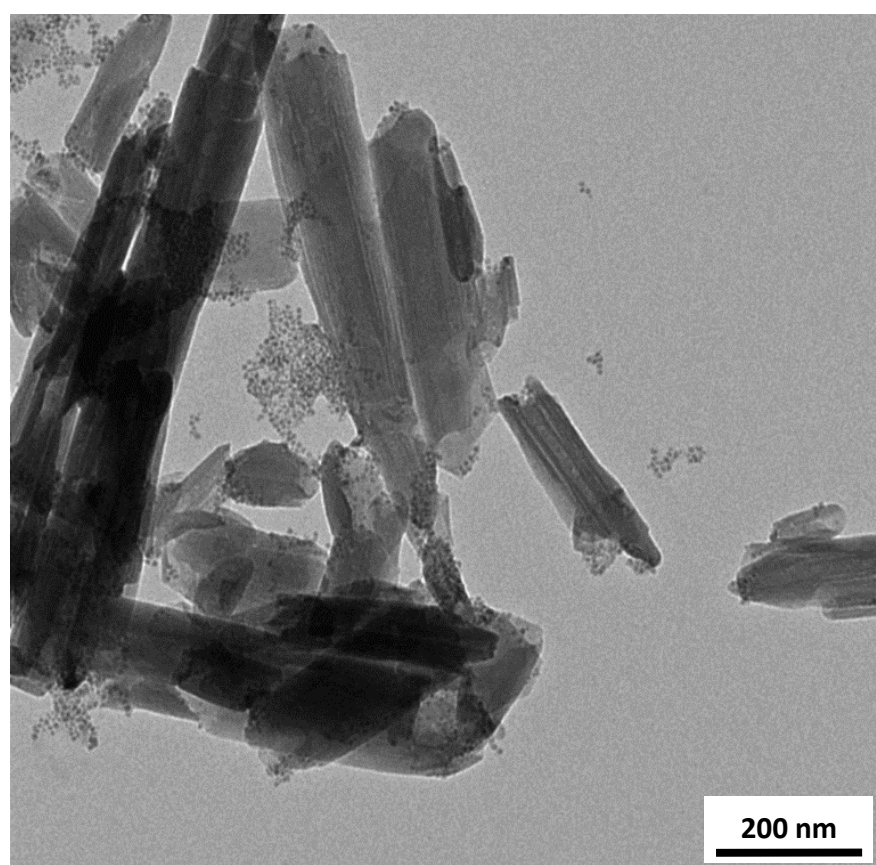

Figure S8b. TEM micrograph of pristine HNT treated with SPION@PA in water suspension by vacuum/nitrogen cycles. 
5.1 Ligand exchange OA/DMSA (SPION1@DMSA, SPION2@DMSA, and SPION3@DMSA). The ligand exchange procedure was carried out following a procedure developed by some of us. ${ }^{4} \mathrm{~A}$ sample of SPION@OA suspended in n-hexane containing a total amount of $5 \mathrm{mg}$ Fe $(1.5 \mathrm{~mL}$ SPION1, $1.25 \mathrm{~mL}$ SPION2, and $2.3 \mathrm{~mL}$ SPION3) was treated with $4 \mathrm{~mL}$ of acetone and centrifuged (4 min $7197 \mathrm{rcf}$ ) to remove the excess of oleic acid. The nanoparticles were re-suspended in $9 \mathrm{~mL} \mathrm{n}$-hexane and transferred in a Schlenk tube under nitrogen atmosphere. To this suspension a solution of DMSA dissolved in acetone (50 $\mathrm{mg}$ in $9 \mathrm{~mL}$ ) was added, followed by $15 \mu \mathrm{L}$ of triethylamine (TEA). The suspension in the Schlenk tube was then moved to an ultrasonic bath and the reaction mixture was kept at $54{ }^{\circ} \mathrm{C}$ for $40 \mathrm{~min}$, maintaining the suspension under nitrogen atmosphere for the whole sonication time. The SPION were then collected with a magnet, re-suspended in $20 \mathrm{~mL}$ of acetone and centrifuged for $10 \mathrm{~min}$ at a rate of $7197 \mathrm{rcf}$. The last wash was carried out by re-suspending the pellet in $20 \mathrm{~mL}$ of milliQ water and centrifuged again (30 min, $7197 \mathrm{rcf}$ ). The washed SPION were finally resuspended in $10 \mathrm{~mL}$ of milliQ water and stored under nitrogen atmosphere at $4{ }^{\circ} \mathrm{C}$ or at room temperature for further uses.

5.2 Ligand exchange OA/GA (SPION4@GA). ${ }^{5}$ A sample of SPION@OA suspended in n-hexane (2.6 $\mathrm{mL}, 5 \mathrm{mg} / \mathrm{mL} \mathrm{Fe}$ ) was re-dispersed in $10 \mathrm{~mL}$ toluene. Gallic acid (GA) (43.2 mg, $0.254 \mathrm{mmol}$ ) was dissolved in a mixture of $110 \mu \mathrm{L}$ pyridine and $322 \mu \mathrm{L}$ toluene under 5 min sonication. Then, GA solution was added dropwise into SPION suspension, and the SPIONs precipitated immediately. The SPION@GA were then recovered by a permanent magnet and the supernatant was removed. The magnetic pellet was then re-suspended in $10 \mathrm{~mL}$ of $1 \%$ sodium carbonate solution, then SPION@GA were washed by adding an excess of ethanol $(20 \mathrm{~mL})$ and collecting the precipitating SPIONs by centrifugation (7197 rcf, $2 \mathrm{~min}$ ). The pellet was then re-suspended in $3 \mathrm{~mL}$ water, precipitated again by adding ethanol and collected by centrifugation (7197 rcf, $2 \mathrm{~min}$ ). Then, the resulting SPION@GA pellet was easily re-dispersed in $10 \mathrm{~mL}$ water, and stored at $4{ }^{\circ} \mathrm{C}$ for further uses. The same procedure has been used for the exchange OA/PA.

5.3 Ligand exchange OA/TMAOH (SPION4@TMAOH). ${ }^{6}$ A sample of SPION@OA was suspended in nhexane $\left(2.6 \mathrm{~mL}, 5 \mathrm{mg} / \mathrm{mL} \mathrm{Fe}\right.$ ) and dried under $\mathrm{N}_{2}$ stream in a glass vial. The solid residue was treated with an aqueous solution $\mathrm{TMAOH} \cdot 5 \mathrm{H}_{2} \mathrm{O}(1.25 \mathrm{~mL} 1.1 \mathrm{M})$ and ultra-sonicated at $54^{\circ} \mathrm{C}$ for $40 \mathrm{~min}$ for redisperse the SPION@TMAOH. After sonication, the suspension was diluted with $10 \mathrm{~mL}$ MilliQ water and further sonicated affording a clear brown suspension (final concentration of $\mathrm{Fe}_{3} \mathrm{O}_{4} @ \mathrm{TMAOH} 0.5$ $\mathrm{mg} / \mathrm{mL})$.

5.4 Attempts to load SPION@DMSA into HNT lumen. Water suspended SPION@DMSA (0.5 mg/mL) at $\mathrm{pH}$ 3-4 was mixed with $1 \mathrm{~mL}$ of HNT water suspension $(10 \mathrm{mg})$ at the same acid $\mathrm{pH}$ value. The mixture was sonicated for $15 \mathrm{~min}$, shaken on a vortex for $10 \mathrm{~min}$, and then the suspension subjected 
to reduced pressure $(30 \mathrm{mmHg})$ for $30 \mathrm{~min}$ at room temperature. The sonication vacuum process was repeated for 5 times, giving rise to a brown HNT adduct affected by an external magnet, which was recovered by centrifugation ( $3 \mathrm{~min}, 470 \mathrm{rcf}$ ). The same procedure was used for the attempts of loading of the other SPION (SPION@GA, SPION@PA, SPION@TMAOH).

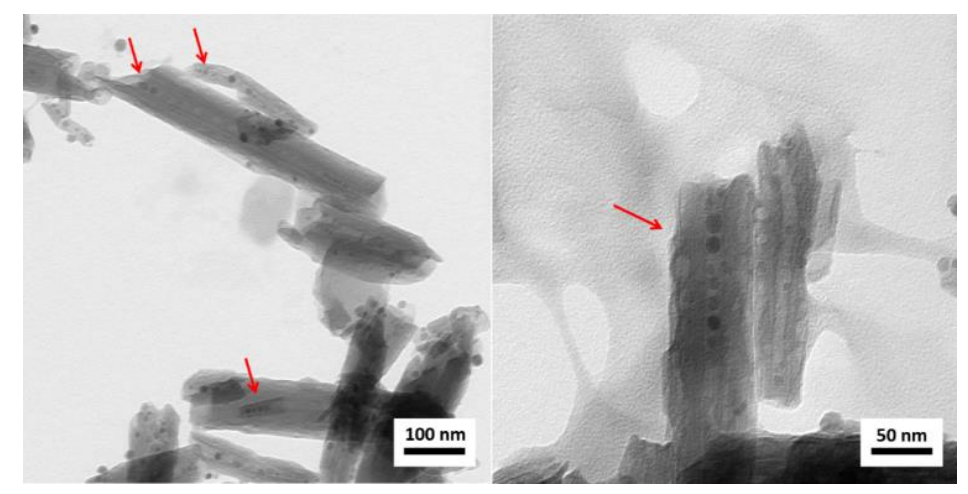

Figure S9. TEM images of HNT-SPION adduct obtained by thermal decomposition of iron precursor in the presence of HNT at high temperature and preceded by a vacuum/nitrogen cycle. Red arrows mark the SPION grown in the inner lumen of HNT.

\section{One-pot procedure with thermal decomposition synthesis of SPION in the presence of HNT. The} synthesis was carried out by following a slightly modified literature procedure, ${ }^{2}$ and in the presence of HNT. Birefly, in a two-neck round-bottom flask, under nitrogen atmosphere, Fe(acac) $)_{3}(0.353 \mathrm{~g}, 1$ $\mathrm{mmol})$ and HNT $(0.706 \mathrm{~g})$ were added to benzyl ether $(10 \mathrm{~mL})$ such that the mass ratio Fe: HNT was 1:2. The mixture was magnetically stirred for $10 \mathrm{~min}$, then sonicated for $15 \mathrm{~min}$ and subjected to a reduced pressure ( 1-2 mmHg) under stirring for $30 \mathrm{~min}$. The sonication-vacuum- $\mathrm{N}_{2}$ cycle was repeated for 2 times more. Finally, $1.435 \mathrm{~g}$ of 1,2-hexadecanediol ( $5 \mathrm{mmol}$ ) together with $0.952 \mathrm{~mL}$ of oleic acid $(3 \mathrm{mmol})$ and $0.987 \mathrm{~mL}$ of oleylamine $(3 \mathrm{mmol})$ were added and mixed under inert atmosphere. The magnetic stirrer was removed and the mixture heated from room temperature to $200{ }^{\circ} \mathrm{C}$ at a heating rate of $15^{\circ} \mathrm{C} / \mathrm{s}$. Then, the mixture was left at $200^{\circ} \mathrm{C}$ for $2 \mathrm{~h}$, and then further heated up to $300{ }^{\circ} \mathrm{C}$ at the same rate as before and left at this final temperature for $1 \mathrm{~h}$. At the end of the heating period the black-dark brown mixture was left to cooling down naturally to room temperature by removing the heat source. The so-obtained suspension was precipitated with ethanol $(20 \mathrm{~mL})$, then the black precipitate was recovered by centrifugation (10 min at $4226 \mathrm{rcf}$ ). The precipitate was resuspended in $20 \mathrm{~mL} \mathrm{n}$-hexane adding also $50 \mu \mathrm{L}$ oleic acid and $50 \mu \mathrm{L}$ oleylamine. Centrifugation (10 min at $4226 \mathrm{rcf}$ ) was applied to remove possible free SPION or SPION externally interacting with the HNT. The SPION-in-HNT product was treated with ethanol, and centrifuged again (4226 rcf, $10 \mathrm{~min}$ ) to remove all the high-boiling solvent or the surfactant excess. Then the solid was re-dispersed in $35 \mathrm{~mL}$ $\mathrm{n}$-hexane and left under nitrogen atmosphere. After 2 days of decantation, the black supernatant 
containing free SPION@OA was carefully removed. The solid residue was dried under vacuum and grinded, thus obtaining a grey and magnetic precipitate.

7 Attempt to Load SPION into unmodified pristine HNT lumen (SPION@OA-in-HNT). In a Schlenk tube a sample of SPION3@OA (0.5 mL, $2.2 \mathrm{mg} / \mathrm{mL}$ ) were mixed with $20 \mathrm{mg}$ HNT in $20 \mathrm{~mL}$-hexane. The suspension was shaken for $1 \mathrm{~min}$ by a vortex, then it was cooled at $0{ }^{\circ} \mathrm{C}$, and while standing in the ice bath, it was placed under reduced pressure and magnetic stirring until the solvent was visibly reduced. Then, another $20 \mathrm{~mL} \mathrm{n}$-hexane was added. After $1 \mathrm{~h}$ of the cycle reducing pressure, the brown color of the supernatant due to the magnetic NPs remained unchanged with respect to the starting color. The HNT/SPION were recovered by centrifugation ( $3 \mathrm{~min}, 470 \mathrm{rcf}$ ), the supernatant removed and the precipitate washed with $5 \mathrm{~mL}$-hexane.

a)

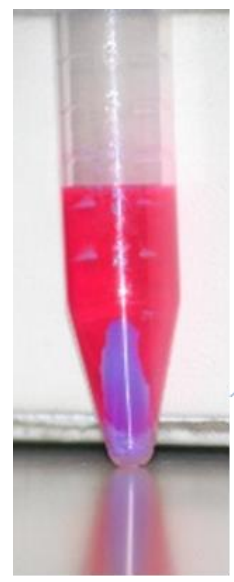

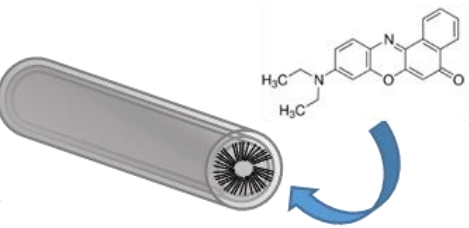

Halloysite-TDP

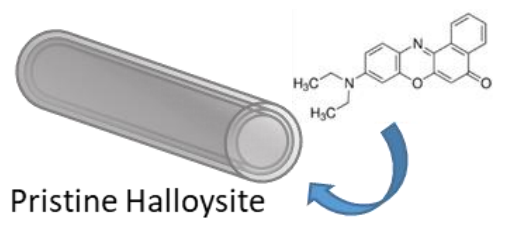

Washed and suspended in water.

b)

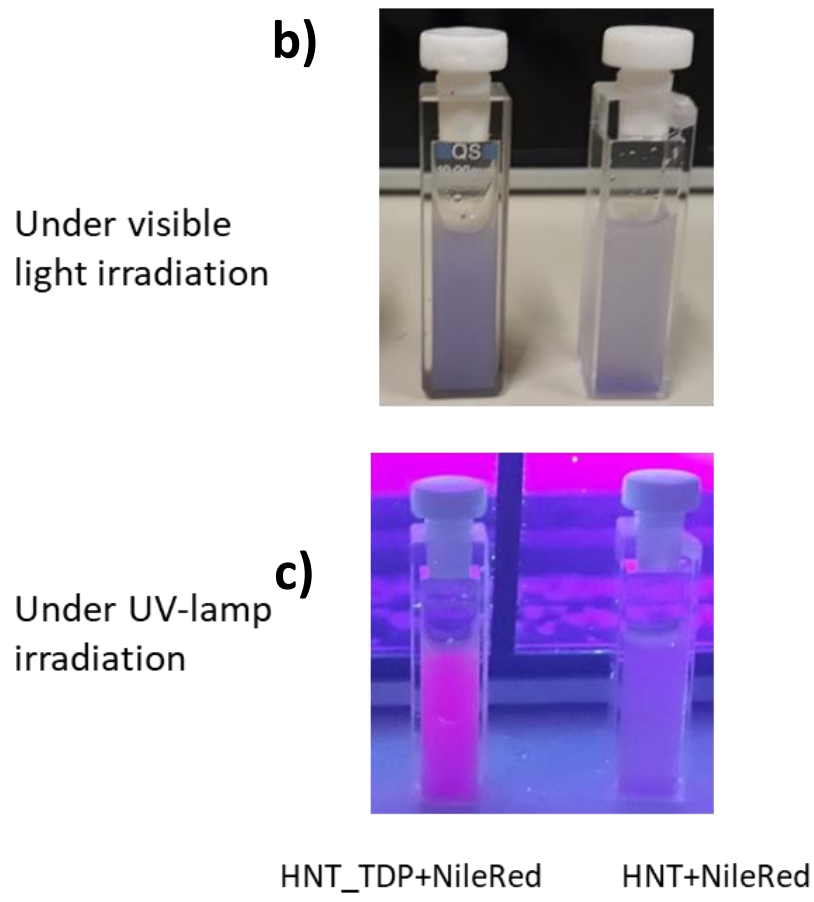

Under visible light irradiation

Figure S10. Digital pictures showing (a) the HNT interacted with an ethanol solution of Nile Red dye; (b) HNTTDP (left) and pristine HNT (right) treated with Nile Red and irradiated by visible light; (c) the same samples of panel (b) irradiated by UV-light. 
Size Distribution by Intensity

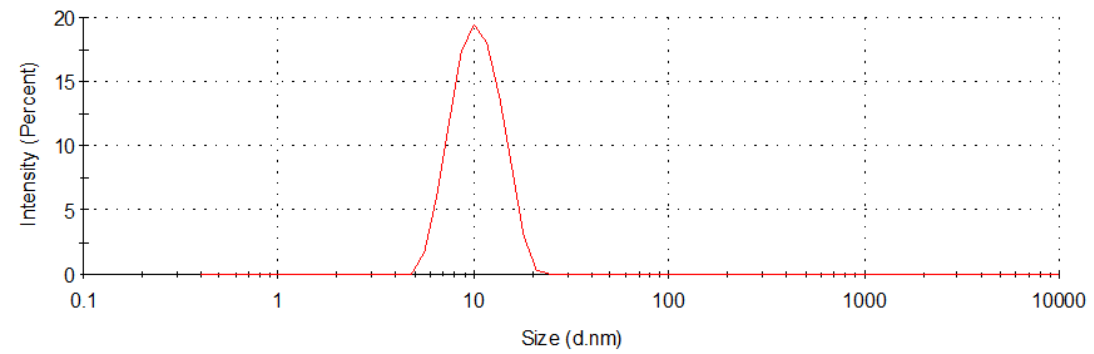

Figure S11. DLS of SPION3@OA suspended in n-hexane, synthesised by thermal decomposition and then used for the loading in the HNT-TDP.

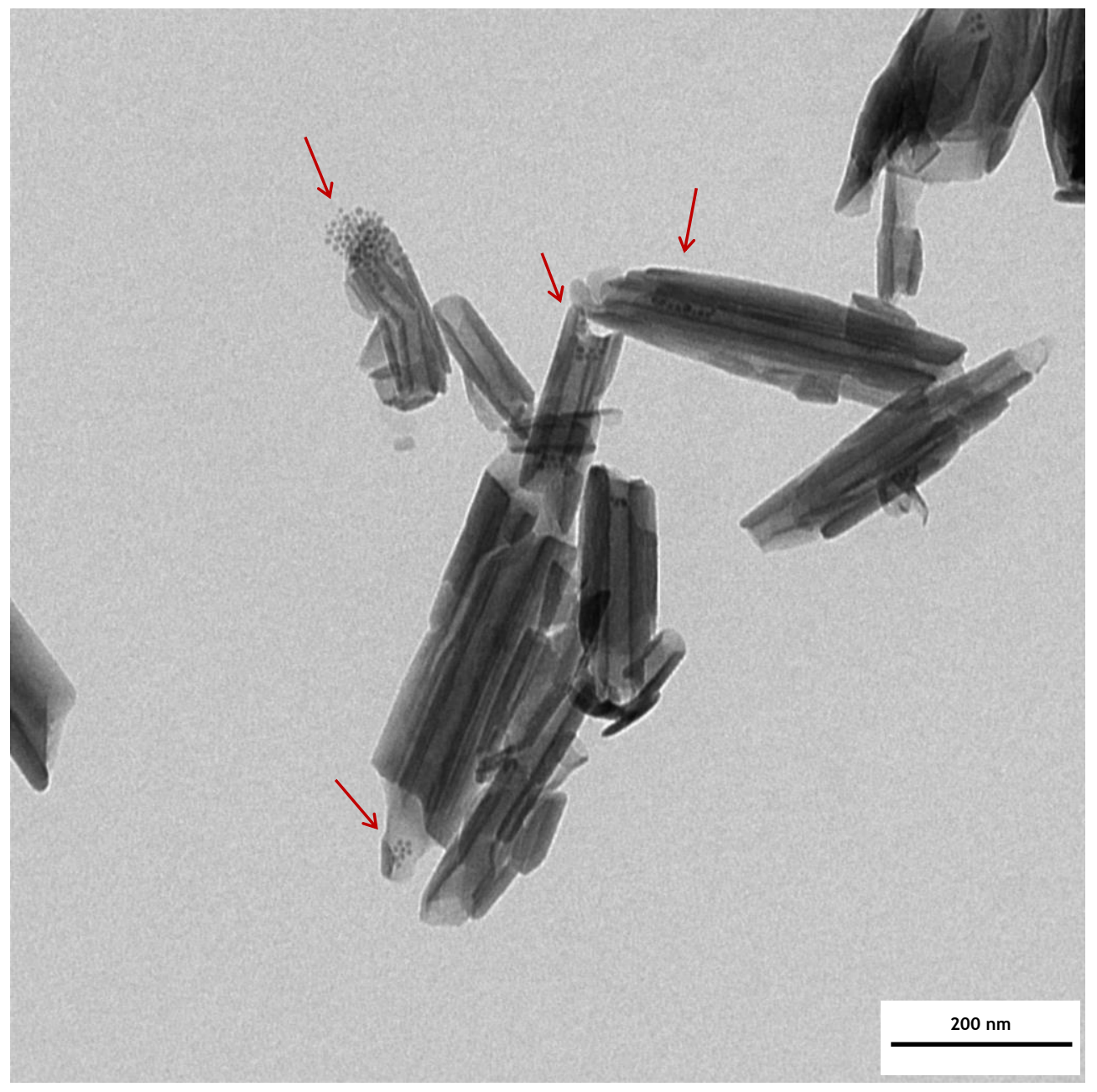

Figure S12. TEM micrograph of pristine HNT treated with SPION3@OA in n-hexane and with several repeated vacuum cycles. Red arrows indicate the sites of SPIONs accumulation. 


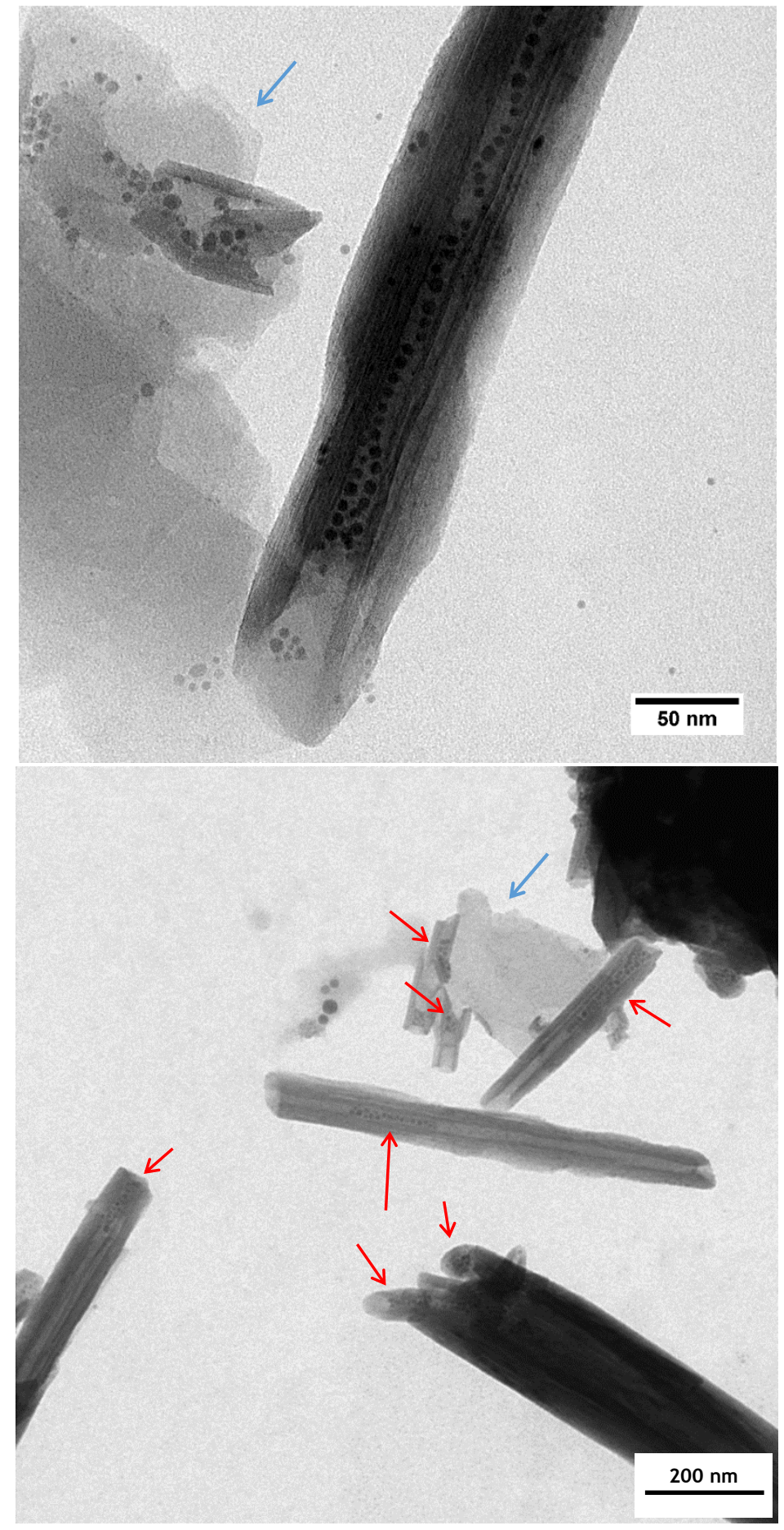

Figure S13. TEM micrographs of HNT-TDP treated with SPION3@OA in n-hexane and with several repeated vacuum cycles. Red arrows indicate the sites of SPIONs accumulation, while the light blue arrows indicate kaolin-like sheets. 


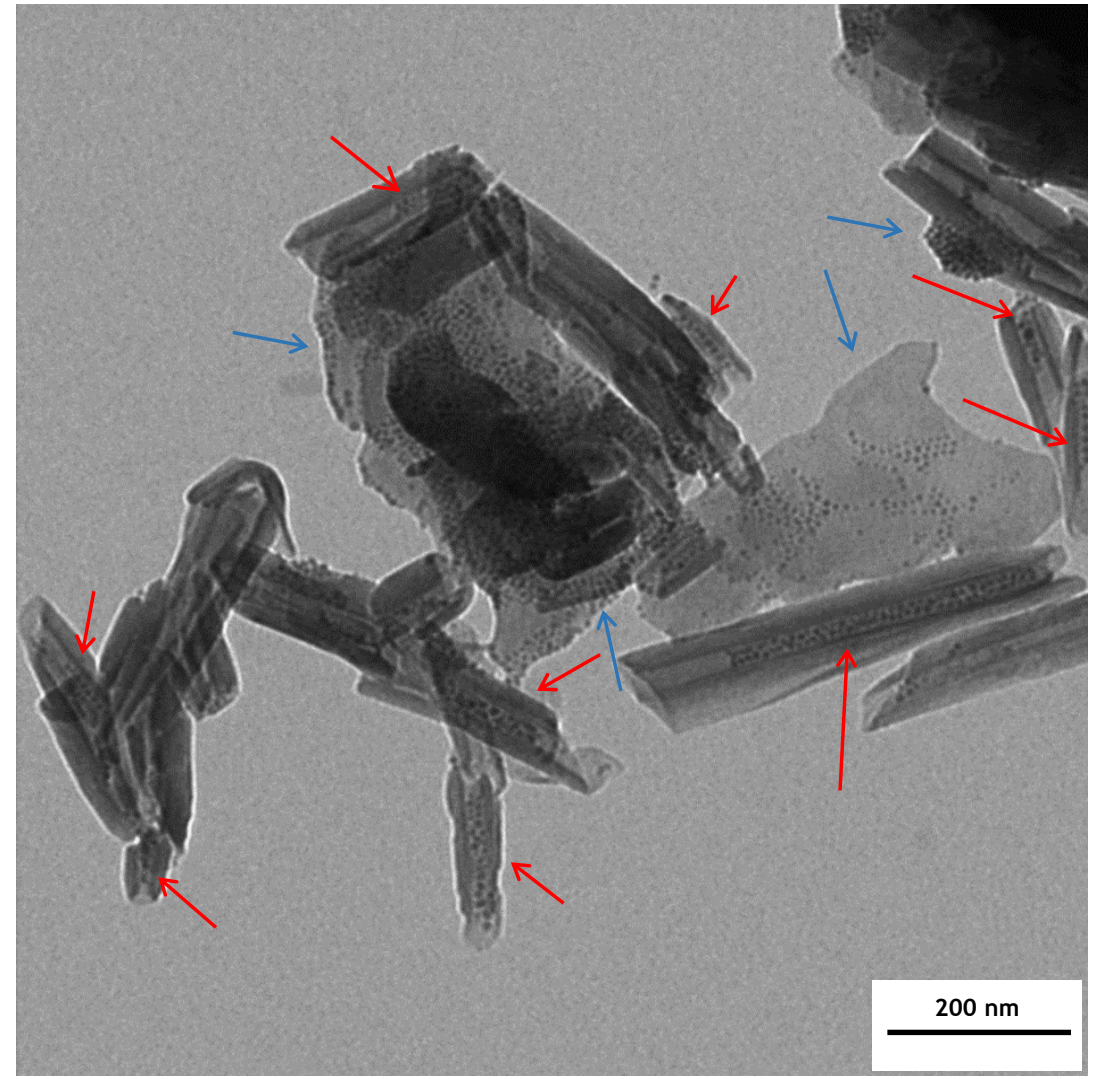

Figure S14. TEM micrographs of HNT-TDP treated with a double amount of SPION3@OA in nhexane and with several repeated vacuum cycles. Red arrows indicate the sites of SPIONs accumulation, while the light blue arrows indicate kaolin-like sheets. 


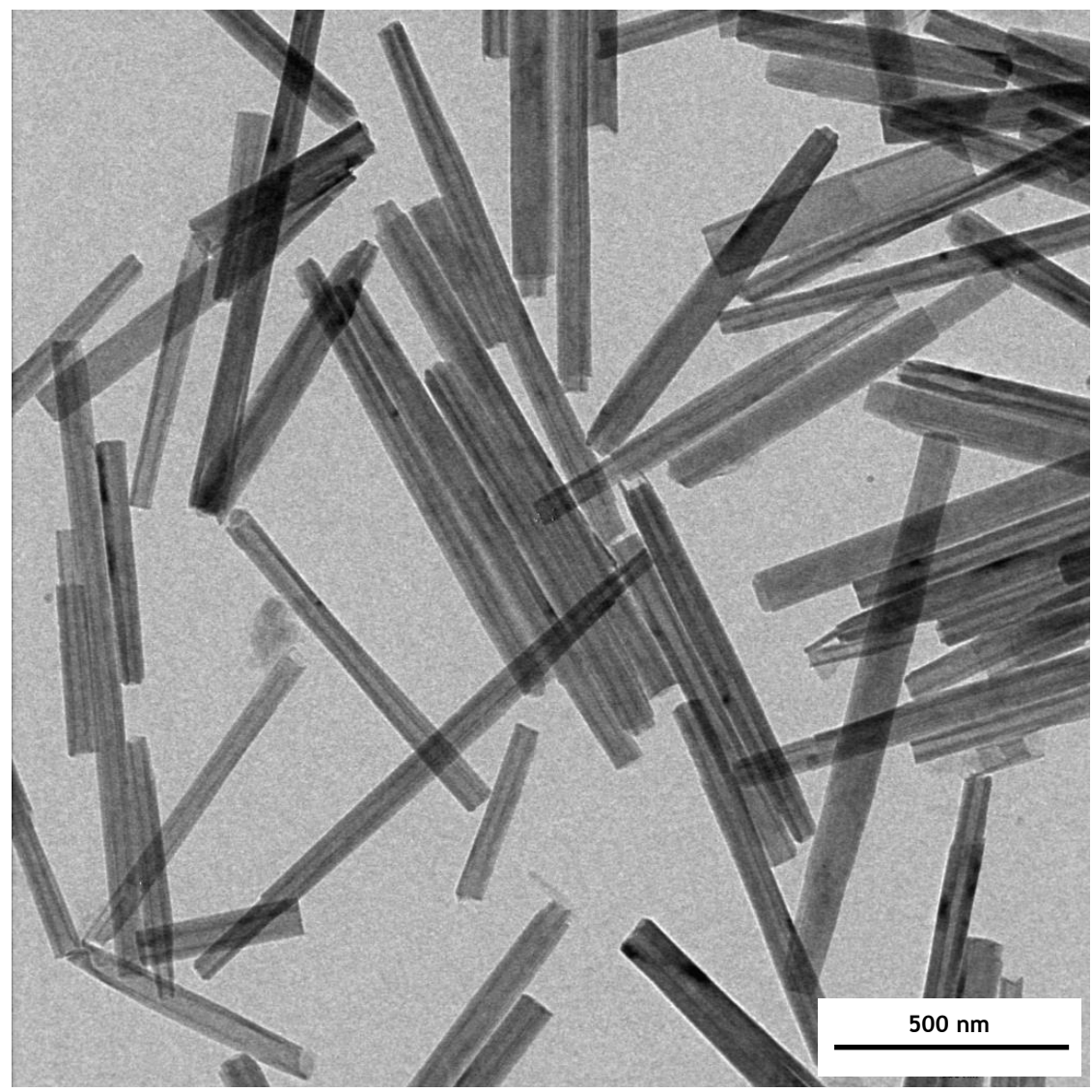

Figure S15. TEM micrographs of A-HNT (Australian HNT). 


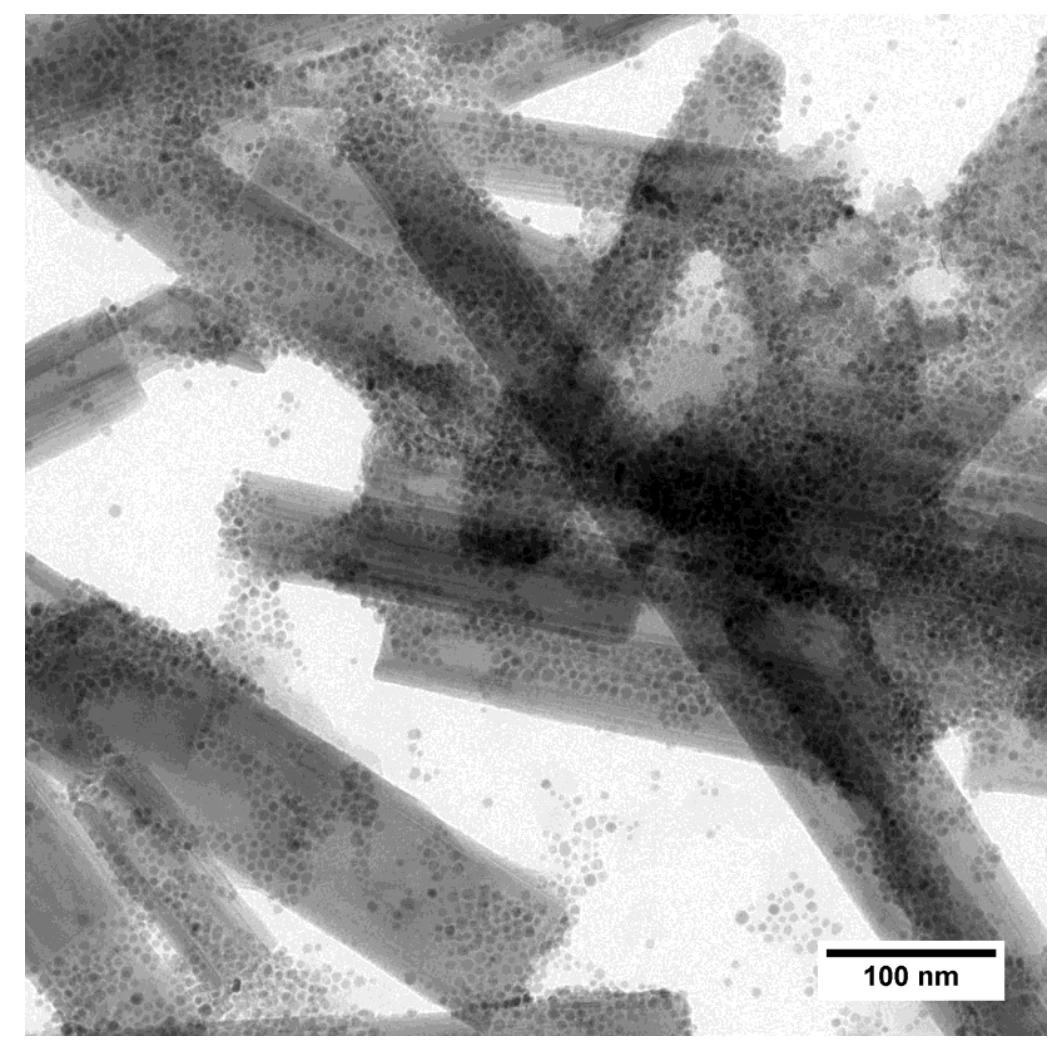

Figure S16. TEM micrographs of A-HNT-TDP treated with a double amount of SPION3@OA in $\mathrm{n}$-hexane and with several repeated vacuum cycles.

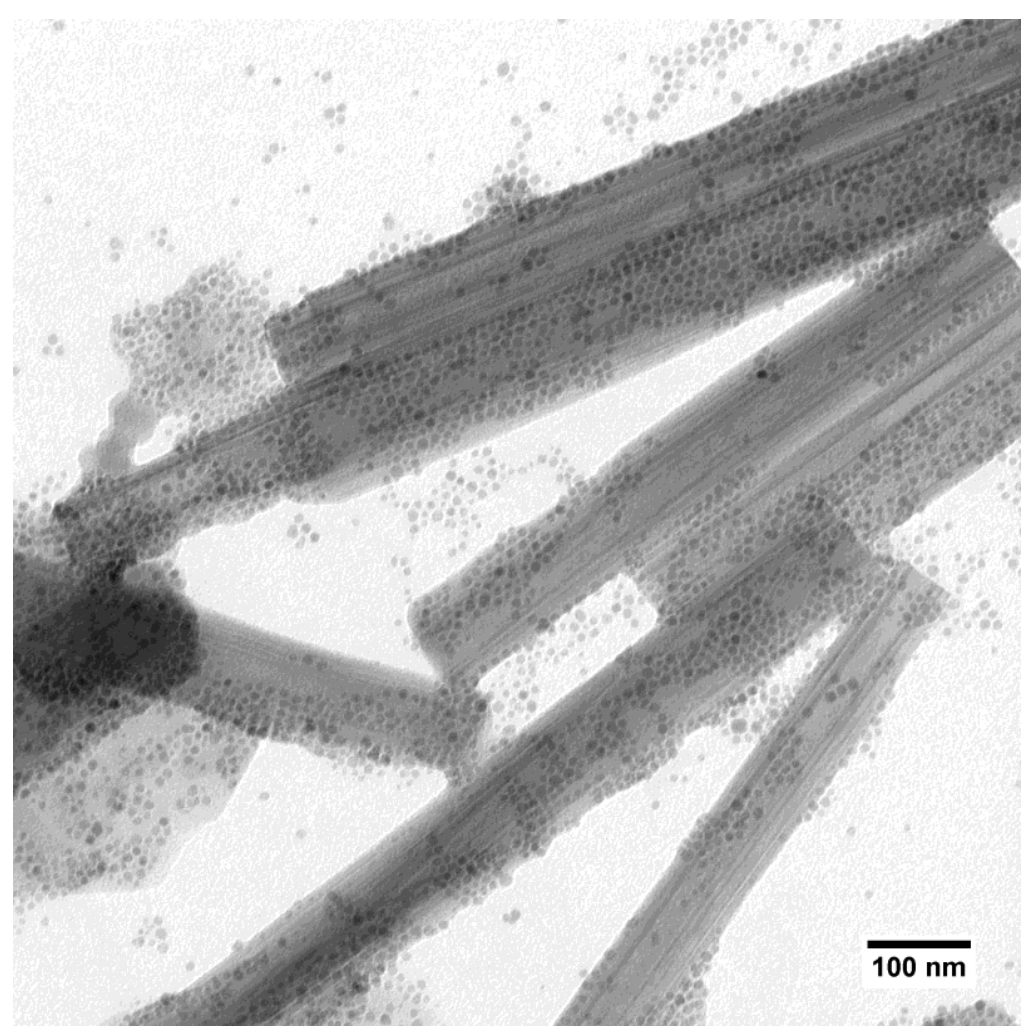

Figure S17. TEM micrographs of A-HNT-TDP subjected to a pre-vacuum-nitrogen cycle and then treated with SPION3@OA in n-hexane and with several repeated vacuum cycles. 


\section{References}

(1) Jiang, W.; Wu, Y.; He, B.; Zeng, X.; Lai, K.; Gu, Z. Effect of Sodium Oleate as a Buffer on the Synthesis of Superparamagnetic Magnetite Colloids. J. Colloid Interface Sci. 2010, 347 (1), 17. https://doi.org/10.1016/j.jcis.2010.02.055.

(2) Sun, S.; Zeng, H.; Robinson, D. B.; Raoux, S.; Rice, P. M.; Wang, S. X.; Li, G. Monodisperse MFe 204 (M = Fe, Co, Mn) Nanoparticles. J. Am. Chem. Soc. 2004, 126 (1), 273-279. https://doi.org/10.1021/ja0380852.

(3) Kim, B. H.; Lee, N.; Kim, H.; An, K.; Park, Y. Il; Choi, Y.; Shin, K.; Lee, Y.; Kwon, S. G.; Na, H. Bin; et al. Large-Scale Synthesis of Uniform and Extremely Small-Sized Iron Oxide Nanoparticles for High-Resolution T 1 Magnetic Resonance Imaging Contrast Agents. J. Am. Chem. Soc. 2011, 133 (32), 12624-12631. https://doi.org/10.1021/ja203340u.

(4) Galli, M.; Guerrini, A.; Cauteruccio, S.; Thakare, P.; Dova, D.; Orsini, F.; Arosio, P.; Carrara, C.; Sangregorio, C.; Lascialfari, A.; et al. Superparamagnetic Iron Oxide Nanoparticles Functionalized by Peptide Nucleic Acids. RSC Adv. 2017, 7 (25), 15500-15512. https://doi.org/10.1039/C7RA00519A.

(5) Hao, R.; Yu, J.; Ge, Z.; Zhao, L.; Sheng, F.; Xu, L.; Li, G.; Hou, Y. Developing Fe3O4 Nanoparticles into an Efficient Multimodality Imaging and Therapeutic Probe. Nanoscale 2013, 5 (23), 11954-11963. https://doi.org/10.1039/c3nr04157c.

(6) Galli, M.; Rossotti, B.; Arosio, P.; Ferretti, A. M.; Panigati, M.; Ranucci, E.; Ferruti, P.; Salvati, A.; Maggioni, D. A New Catechol-Functionalized Polyamidoamine as an Effective SPION Stabilizer. Colloids Surfaces B Biointerfaces 2019, 174 (October 2018), 260-269.

https://doi.org/10.1016/j.colsurfb.2018.11.007. 